\title{
The Role of Context in the Evolution of a Serial Entrepreneur
}

\author{
David J. Bechtold \\ Metropolitan State University of Denver \\ Rajendra Khandekar
Metropolitan State University of Denver \\ Adam Melnick \\ Metropolitan State University of Denver
}

\begin{abstract}
Entrepreneurial research often focuses on the psychological traits of the entrepreneur but rarely on the notion that under certain circumstances entrepreneurship may be equally driven by external factors beyond the founder's control. This paper looks at the 40-year history of a serial entrepreneur and identifies five types of business ventures driven by contextual factors and the personal attributes of the entrepreneur. These five types are the "advised" venture, the "safe harbor" venture, the "accidental" venture, the "greener grass" venture, and the "passion" venture. The paper closes with a call for future research to include situational context in defining what creates and motivates entrepreneurs.
\end{abstract}

Keywords: entrepreneurship, serial entrepreneurship, contextual factors

\section{INTRODUCTION}

The nature of an entrepreneur has been a topic of academic interest for several decades. Most studies have looked at the role that personality plays in developing an entrepreneur (Schjoedt \& Baton, 2007; Baer, 2015; Rauch \& Freez, 2007; Zhao et al, 2010). Other areas include entrepreneurial alertness and risk preference (Karabey, 2010), self-efficacy and prospect theory (Hsu et al, 2017), skill sets (Bonnstetter, 2012), action theory (Frese, 2009), and neuro-cognition (Nejati \& Shahriar, 2013).

The Enterprise Council on Small Business (BtoB, 2009) proposed that entrepreneurs could be classified into three basic profiles:

1. Mountain Climbers ( $2 \%$ of small business owners)- entrepreneurs motivated by growth and achievement.

2. Freedom fighters (24\% of owners) - "corporate refugees" seeking life beyond the company.

3. Craftspeople (76\% of owners) - people that form a business to pursue their trade.

Perhaps the most interesting way to classify entrepreneurs has been offered by Barclay's in their report entitled The Psychology of Entrepreneurship (2015) who identified entrepreneurs as either type A (artistic, well-organized, highly competitive, emotionally stable, neither extroverted nor introverted) or type B (traditional, spontaneous, team-working, emotional or in touch with emotions, and neither extroverted nor introverted). The study also offered that some people want to be entrepreneurs to satisfy issues related to 
locus of control and self-efficacy while others became entrepreneurs due to circumstances outside of their control. It is these "necessity entrepreneurs" that are driven to start a business due to the context of their situation.

The following case describes a serial entrepreneur who exhibits all the personality characteristics that drive entrepreneurship, but also experienced situations where the need to start a new business may have been greater than the drive to start one.

\section{FORTY YEARS AS AN ENTREPRENEUR}

Dr. John Francis (alias) has been a serial entrepreneur for over 40 years. He exhibits the prerequisite traits of a serial entrepreneur as he moves from business to business (Goldman, 2017). However, as he describes his motivations for starting each of his business ventures, it becomes clear that an integral part of his decisions to pursue the venture was not just the recognition of a new opportunity but also the specific circumstances surrounding him that motivated the new business venture.

The following case describes the experiences of Dr. Francis during his career as a medical provider and as a serial entrepreneur, as well as the type of entrepreneurial response he pursued. We will describe the context of each new business venture decision as well as the outcome that Francis experienced. We will propose that in some instances Francis pursued a business venture based on his passion for the idea he conceived, but in other cases he pursued a venture out of necessity.

\section{The Beginning of a Serial Entrepreneur - A Series of Unconnected Events}

In the late 1960's John Francis entered law school with the intent of becoming a lawyer. A hand injury forced him to leave school and he returned to an initial passion, carpentry, and began work as a home builder. After a year, he was invited to join a partnership that speculated in home construction. He declined the offer feeling that the commitment was too great and the risk too large. After a brief attempt at being a business consultant Francis returned to graduate school.

Francis applied to a psychology program, in response to a personal interest, as well as a business program in the hopes of being accepted into one. In fact, he was accepted into a joint psychology and business degree program. Unfortunately, the joint psychology/business degree program was dissolved after his first year in graduate school forcing Francis to decide to pursue a psychology graduate degree. With his full-time commitment to the psychology program Francis was told by his professors to abandon his studies in business and focus solely upon his training in psychology, and then to start a practice.

As he continued his graduate studies Francis came to realize that he wanted to pursue a Ph.D. in psychology. As part of the degree requirements Francis would be required to pass a Graduate Record Exam in a second language. Francis convinced his department to accept a computer programming language (FORTRAN) in lieu of a traditional foreign language to meet this requirement.

Upon graduation a foundation as an entrepreneur for Dr. Francis had been formed. A passion for psychology and psychotherapy, an expertise in FORTRAN computer programming language as well as a growing interest in computers and software development, a basic understanding of business principles, and an appreciation for carpentry. Francis would draw upon these seemingly disconnected skills and interests to not only develop his skill as a psychotherapist but also as a serial entrepreneur.

However, one element was still missing, the recognition of an opportunity that provided the necessary reward for risk and the effort that Dr. Francis would be required to make. For this Francis would need to rely not only on his personal skills and abilities but also upon the skills and abilities of others. First as advisors, then as partners, and finally as support. Ultimately the context of these relationships would help Francis not only pursue a venture but also exit from it and replace it with something new and more aligned with his developing skills and experience. 


\section{The Advised Venture}

Once he completed graduate school Dr. Francis found himself with some available capital. He was advised to invest in real estate to reduce his taxes. This advice seemed attractive given Francis' experience in the construction industry.

Francis purchased a home that had been converted into four rental units. The house was in a depressed part of town and had experienced a significant reduction in price, making the investment financially attractive. Francis drew upon his construction experience to personally do most of the needed renovation and ultimately served as the property manager. When he needed to leave the city, Francis hired an experienced property manager to oversee the day-to-day management of the property. He maintained this venture for 35 years. In addition to the rental income, Francis experienced a windfall when he sold a portion of the property to a developer and, ultimately, a significant capital gain when he finally sold the property.

Dr. Francis first venture was uncommon for a serial entrepreneur in that he maintained it for such a long time. However, it was a venture in a field that he had previous experience with, in a city that he knew and felt comfortable in, and most importantly a venture he could turn over to another to do the daily management thus freeing his time to pursue his next venture. However, it was a venture he did not pursue on his own but only after he had received the recommendation of a trusted advisor.

The advised venture is one that an entrepreneur enters based upon the influence of a trusted other. Oftentimes this influence occurs early in one's career and is motivated more for practical reasons rather than by recognizing an unrealized opportunity. The entrepreneur must be comfortable with the advice that they are receiving. For Dr. Francis this comfort came in both a confidence in his personal abilities and the fact that it was in a familiar industry. Often the venture that presents itself is not something that the entrepreneur would consider without this trusted advice.

It is this combination of trust, confidence, and opportunity that motivates the creation of the advised venture which can often be in an industry outside of the entrepreneur's formal training. As entrepreneurs become more confident in their own abilities to identify opportunity the use of trusted advisors to direct entrepreneurial activity will change and will be reduced. This is particularly true if this advised entrepreneurial venture is a failure. However, in Dr. Francis case, this venture proved to be one of his most successful providing him with income and windfall profits for 35 years and ultimately a significant return on investment when he sold the property.

\section{The Safe Harbor Venture}

Once Dr. Francis completed his licensure requirements, he was ready to begin to practice his profession. Like many new entrepreneurs in professional services, he did not feel he had the time to start a professional practice as well as oversee all the practical business duties necessary to sustain an independent practice. For these reasons, Francis was faced with three possible options to begin his career. He could seek employment in a psychiatric care facility, start his own individual practice, or join a practitioner group.

In 1980, Francis chose to join a group of psychiatric practitioners that offered him the time and independence to develop his own practice while providing him, for a fee, professional space and billing services. Francis was still responsible for the other services associated with the practice including client recruitment, recordkeeping, and of course providing the therapeutic service. By removing some of the burden of starting and maintaining a practice Francis was also allowed to continue to develop his interest in neurofeedback as a treatment modality.

While initially the relationship took some of the daily burdens of running a medical practice away from him, soon Dr. Francis experience with the practitioners group became more and more difficult. He lost money due to delays in billing, which prompted him to hire his own part-time billing clerk, as well as experienced increasing frustration due to his lack of input into management policies and practices.

These frustrations eventually led Francis to change practitioner's group, joining one that was larger and more professionally managed. This new group provided Francis with the physical space needed to continue to expand his practice, as well as add new treatment modalities in the use of neurofeedback techniques. These experiences also allowed Francis to continue to develop the experience and business acumen necessary to start his own private practice. 
The safe harbor venture allows entrepreneurs to establish protective barriers on some aspect of their business that they feel they do not have the time, expertise, or financial wherewithal to provide for themselves. Outside of professional practices the safe harbor venture allows young entrepreneurs the opportunity to be part of an entrepreneurial venture without assuming all the risks and responsibilities needed to make the venture a success. Often the safe harbor venture serves as a crossroads where some possible entrepreneurs, after seeing and experiencing what entrepreneurs must do to make their venture a success, choose to become involved as employees in larger organizations. Others, however, are now more prepared to start their own independent venture. For the serial entrepreneur, the challenges associated with not having independence nor the revenue stream that they expect prepares them to act independently.

\section{JF Life Balance, LLC (Fictitious Name)}

The combination of increasing experience and confidence in his own abilities coupled with a growing dissatisfaction with the support and services he was receiving positioned Dr. Francis to move out from his safe harbor ventures. Francis came to realize that he was better off being in complete control and fully responsible for the future ventures which led in 1997 to the formation of his first venture JF Life Balanced, LLC. JF Life offered health and performance optimization strategies based upon psychophysiology and mental health practices.

As Dr. Francis moved to a private practice, he continued to look for ways to increase revenue for his firm. He served as an expert witness in litigations, where fees were billed to attorneys instead of to insurance companies and developed a robust referral network that included attorneys and medical providers as well as non-competing psychologists. However, the limitations of the professional service provider where fees are directly correlated to time continued to have an adverse effect on his practice. Additionally, developing other complementary revenue streams such as selling goods and services from providers that you have a business relationship with, is discouraged by his profession, is often considered unethical, and can even put the license to practice at risk. This was the conundrum facing Francis as he tried to find ways that would generate additional revenue to grow his business.

In the early 1990's, before the start of JF Life, Francis continuing interest in biofeedback and neurofeedback treatment modalities prompted him to add this into his practice. As his expertise in neurofeedback grew so did the industry acceptance of the modality as a possible treatment option for people recovering from traumatic brain injury or other mental or physical maladies. In addition to increasing his scope of services, neurofeedback treatments changed his revenue mix by adding a significant level of patient self-pay services.

As biofeedback and neurofeedback became commonplace in psychotherapy, more vendors began to offer various computer-based feedback systems. The lack of a common platform made it hard for these systems to interface and frequently led to equipment downtime and lost treatment revenue. Adding to the complexity of the systems was that these systems were not developed to be user friendly and had simplistic graphics and rudimentary control parameters. Trying to resolve the difficulties in the technology led to a chance encounter and Francis' next venture.

\section{The Accidental Venture}

A chance conversation with a software programmer that Francis hired to help modify a neurofeedback system indicated that a 3D graphics interface could significantly enhance performance. Francis quickly recognized that a product enhancement such as this would be a unique product offering as well as provide Francis with a first mover advantage if he could develop and get it to market. Adding to this potential advantage was Francis continuing interest in computer software programming and a developing network of clinicians interested in biofeedback as a potential treatment modality.

This new business is based upon enhancing the available bio- and neuro-feedback hardware and software to be more engaging with patients as well as easier for service providers. Adding to the value was the ability to provide a functional display across systems. This new venture was outside of Dr. Francis practice but complementary to it and came about because of this chance conversation. 
The accidental venture is often one that an entrepreneur, especially a professional service provider, discovers as they seek to expand their revenue stream beyond the time-based billing of services. The desire to develop a product that can provide revenue independent of time, as well as achieve scale economies, requires professional service providers to recognize opportunities that are outside of their training and traditional practice activities. Often it is a serendipitous merging of need, ideas, and external expertise. The accidental venture though still has connection to the original business.

For a serial entrepreneur, the accidental venture is a logical extension of an existing venture that becomes a recognizable opportunity once the existing venture becomes operationalized. It is not a quantum leap away from the existing venture but rather a side-step that can often create the comment "why didn't I see this before". It can occur during an attempt to solve a problem or in a casual comment between friends. The challenge is recognizing the opportunity and then conceptualizing a business plan to turn this accidental awareness into a viable venture.

Unfortunately, accidental ventures may disappear as quickly as they appear due to the challenges in moving from a service based to a product base strategy. This was the case for Dr. Francis and his 3D neurofeedback system. Distribution challenges as well as competitive responses, which are often not well defined in these accidental ventures, can create barriers to success and that was certainly the case for his display software company. Even more significant for Francis was over-estimating what turned out to be a limited market of service providers that could use his product. This is the great danger of accidental ventures that are complementary to the primary venture of the serial entrepreneur. As a stand-alone business, the weaknesses of the venture are more apparent and easier to assess and respond to, while as a complementary business the risks become clouded as costs, both in terms of time and money, and become absorbed by the primary business. This can create the flawed impression that the new venture is more viable than it actually is.

\section{The Greener Grass Venture}

Much like an accidental venture the motivation for pursuing a greener grass venture is the frustration of revenue limitations. These limitations can be seen as a limited product line or, for a professional service provider, a ceiling in the number of billable hours for service that can be charged. This desire to expand revenue motivates a serial entrepreneur to try different ventures that not only enhance revenue but also shift the business model. For Dr. Francis, this was the development of an on-line retail site that would sell digital art. Francis felt that his software programming experience which began in college as well as his growing abilities in graphic design would allow him to create an exciting website that could effectively compete with competitors. The intent of this venture was to provide capital to support the neuro-feedback software being developed. Ultimately the effort proved too great for the return and Francis quickly closed the venture to focus on the software venture.

When a serial entrepreneur feels limited in the revenue being generated in their primary venture there is the temptation to add product lines and services or, in the cases of professional service providers, to move into product development and retail sales. For service providers the attraction of this model is that revenue generation isn't encumbered by a fee-based model which is constrained by billable time. There is also personal excitement of moving into different venues and testing an entrepreneur's business acumen. As the parable says, "the grass is always greener on the other side of the fence" and this of course is the same allure for serial entrepreneurs. Often the requirements (time, money, or expertise) of a new independent venture becomes greater than the entrepreneur can provide. For Dr. Francis, the weakness of the venture quickly became apparent, and he extracted himself with just limited financial loss. For other serial entrepreneurs, these greener grass ventures can be perceived as a test of their capabilities and can pose great risk as exit becomes less a business calculation and more a perceived statement of individual incompetence in this new business environment.

\section{The Passion Venture}

Through the years, Dr. Francis continued to invent and consider new ideas to enhance his practice. He had evolved as a business professional and no longer needed safe-harbors, and his knowledge in software 
programming and experience in software development within his field continued to grow. He continued to look at ways that existing software could be enhanced to improve his practice. Such was the case when he asked an electroencephalogram (EEG) brain mapping company for a feature that he felt could enhance his practice and was told by the company that what he asked for was not possible. Weeks later, in the middle of the night, Francis awoke certain that what he asked for was possible, and he knew how to do it. He then began his most important venture, the passion venture.

Passion ventures go beyond just a good idea, or an opportunity not recognized by others. It often is the reason why innovators become entrepreneurs. It is the venture that captures their heart and mind and becomes embedded into their very being. Like a child, it is a venture that they nurture and will stay loyal to even if it fails to develop. For Dr. Francis, it was a multi-year effort to design a product that would answer a pressing need for his industry as well as developing a business model that could market the product to a wider group of users. It was a product that was challenging because not only did he have to design the product, develop the market, and build the business he would need to also get regulatory approval from the Food and Drug Administration (FDA) so that his product could be integrated into treatment modalities.

While the innovation he developed created two patent applications, it also used up countless hours and significant capital as he worked with sub-contractors and consultants. The personal and financial resources were in addition to all that was required to maintain his clinical practice. The product that Francis created was an innovative approach to analyzing and assessing data that was acquired when a practitioner conducted an EEG on a patient.

Before he began his venture he discussed, in general terms, his idea with colleagues and once the concept was understood was excited by the enthusiasm it generated. Based upon this enthusiasm Francis withdrew himself from his practice to focus more upon developing the algorithms and platform software for his new venture. He hired personnel to help with software solutions as well as maintain technical records to support his on-going patent endeavors. Adding to his excitement was that unlike his venture in providing a 3D interface enhancement to bio-feedback devices this product was being described as equivalent to other EEG software devices providing not only an easier path to FDA approval but also a larger market and a sense of higher prestige for the product itself.

Francis' excitement for the product lead him to share his thoughts with colleagues and friends. One close colleague who he shared more detailed information of his innovation ultimately developed a similar product on his own even though he had agreed to keep the conversation secret and had even signed a nondisclosure agreement. This revelation not only put his patent applications in jeopardy but also led to threats of litigation between Francis and his former friend. Still, he pushed on and continued to invest substantial amount of time, money, and energy in developing his passion venture.

When, during a meeting of the Medical Device Manufacturers Association, Francis explained his idea to the new director of the FDA devices branch he was told that he would have no problem getting approval for his product as a biofeedback device, rather than the neurofeedback that his venture was based upon. This opinion by the director was devastating to Francis as he developed the product to support providers who conducted EEG's as part of their practice. Still, he continued believing that once his full approval application was completed and submitted, he would get the FDA approval as an EEG device.

In addition to the application was the creation of a website which would be integral to the "labelling" of the product, a critical component of the application and FDA review. However, the development of the website experienced continuing delays which increased costs and frustrations for Francis. Finally, however, all of the necessary information was completed and ready for FDA review.

Ultimately the FDA ruled that the product was a new concept rather than a product that could be labelled as "substantially equivalent" to prior work in EEG data assessment. This ruling would require significant additional testing and validation studies before it could be offered to the market. The ruling by the FDA effectively ended Dr. Francis passion venture. The cost was extreme, over $\$ 150,000$ in direct costs and seven years of intense effort.

Passion ventures are the most exciting and dangerous business that any entrepreneur can entertain and enter, they are also one of the more common types of ventures for entrepreneurs. The modus operandi of serial entrepreneurs requires the ability to exit a venture and move on to the next whenever conditions 
(positive or negative) warrant. The emotional commitment to a passion venture often clouds rational cost and benefit analysis and effectively slows this rational analysis. The venture becomes embedded into the identity of the entrepreneur and so the decision to exit the venture becomes less about the viability of a business and more about the business acumen of the entrepreneur.

For this reason, the entrepreneur cannot simply exit but rather will invest more resources and, most importantly, more time, to force the venture into a success. It is the passion venture that has led to some of the most successful companies on the globe as we have seen by Apple and Amazon in the U.S. and Alibaba in China. It is also the passion venture that has littered the business landscape with countless failures. Such was the case with Dr. Francis.

For every entrepreneur, there is the recognition that few ventures last forever and most will end in failure. The defining difference between serial entrepreneurs and others in business is their ability to survive and learn from the end of a venture and then utilize that knowledge in the development of the next venture (Chen, 2013). Serial entrepreneurs are inherently survivors and that ability to survive the frequent frustrations of failed ventures is their testament. Of all the success and failures experienced by Dr. Francis surviving and continuing to innovate and grow as an entrepreneur is perhaps the greatest lesson to be learned from his story.

\section{When the Race Is Run}

Today, Dr. Francis has returned to his primary practice, JF Life Balance, the company that evolved when he entered into a partnership as an applied psycho-physiologist. The experiences throughout all his ventures made JF Life Balance stronger and more viable. He continues to add additional and innovative treatment modalities to enhance his practice which is an extension of his entrepreneurial mindset. The practice has become more profitable with higher revenue and lower overhead. As for John Francis, he is now near retirement and looks forward to applying his energy as a serial entrepreneur to more personal aspirations.

\section{CONCLUSION}

Entrepreneurs and entrepreneurship are recognized as critical elements in economic development and job creation. To better understand what makes an entrepreneur, research has focused upon the personal attributes of the individual and how these attributes enhance new business creation. In their report Barclay's mentions a second type of entrepreneur, the "necessity entrepreneur" (The Psychology pf Entrepreneurship, 2015), who become entrepreneurs because they have little or no other choice.

Gender, ethnicity, education level, regions of poverty and limited economic development can all be reasons why people pursue entrepreneurial activities. Context, therefore, may be another reason for new business creation and must be included in any research that attempts to understand what drives new business venture creation.

The experiences of Dr. John Francis indicate that many of his ventures were motivated by contextual factors that included either a recognized weakness in a current business practice, a serendipitous encounter, or a passionate idea. These contextual factors interacted with the personal attributes of Dr. Francis that led him to new business ventures.

With the addition of context, entrepreneurship and entrepreneurial endeavors become more than just the passion of the independent, risk-taking individual but can also be a path taken due to necessity or need. This paper identified several contextual factors that can motivate an entrepreneur to act and in doing so creates a call for expanding entrepreneurial research to consider the role that context plays not only in the creation of "necessity entrepreneurs" but also in the creation of traditional entrepreneurs and serial entrepreneurs. 


\section{REFERENCES}

Baer, D. (2015). Psychologists say successful entrepreneurs have these 4 personality traits. Business Insider. Retrieved from www.businessinsider.com/best-entrepreneur-psychological-profile-20153

Barclays. (2015). The Psychology of Entrepreneurship: A data driven study into the motivation behind new business creation. Retrieved from www.home.barclays/content /dam/barclayspublic/images/newsnewsite/2015/06/Barclays\%20report\%2020150616v1-final.pdf

Bonnstetter, B.J. (2012). New research: The skills that make an entrepreneur. Harvard Business Review. Retrieved from hbr.org/2012/12/new-research-the-skills-that-m

BtoB. (2009). Small Business Psychographics. Retrieved from adage.com/article/btob/small-businesspsychographics/277429/

Chen, J. (2013). Selection and serial entrepreneurs. Journal of Economics \& Management Strategy, 22(2), 281-311.

Frese, M. (2009). Toward a psychology of entrepreneurship - An action theory perspective. Foundations and Trends in Entrepreneurship, 6(6), 435-494.

Goldman, J. (2017). Five traits of phenomenally successful serial entrepreneurs. INC. Retrieved from www.inc.com/jeremy-goldman/5-traits-that-make-serial-entrepreneurs-like-richard-branson-elonmusk-so-successful.html

Hsu, D.K., Wiklund, J., \& Cotton, R.D. (2017). Success, failure, and entrepreneurial reentry: An experimental assessment of the veracity of self-efficacy and prospect theory. Entrepreneurship: Theory and Practice, 41(1), 19-47.

Karabey, C.N. (2012). Understanding entrepreneurial cognition through thinking style, entrepreneurial alertness and risk preference: Do entrepreneurs differ from others? Procedia: Social and Behavioral Science, 58, 861-870.

Nejati, V., \& Shahriar, S. (2013). Letter to Editor: Does the ability to make a new business need more risky choices during decisions? Evidences for the Neurocognitive Basis of Entrepreneurship. Basic and Clinical Neuroscience, 4(4). Retrieved from www.ncbi.nlm.nih.gov/pmc/articles/PMC4202576/

Rauch, A., \& Frese, M. (2007). Let's put the person back into entrepreneurial research: A meta-analysis on the relationship between business owners' personality traits, business creation, and success. Eur. J. Work Organ. Psychol., 16(4), 353-85.

Schjoedt, L., \& Baron, R. (2007). The big five personality dimensions: Do the Big Five Affect Entrepreneurial Success at the personal level? Frontiers of Entrepreneurship Research. Retrieved from digitalknowledge.babson.edu/fer/vol27/iss5/10/

Zhao, H., Seibert, S.E., \& Lumpkin, G.T. (2010). The relationship of personality to entrepreneurial intentions and performance: A meta-review. Journal of Management, 36(2), 381-404. 